\title{
FREQUENCY OF ACCESSORY MENTAL FORAMEN AND MANDIBULAR CANAL VARIATIONS IN DENTAL IMPLANT PATIENTS: A RETROSPECTIVE CBCT STUDY
}

\author{
Hilal Peker Öztürk', Ismail Hakan Avsever², Kaan Gündüz ${ }^{3}$, Mesut Akyol ${ }^{4}$, Kaan Orhan ${ }^{5,6}$ \\ 'Department of Dentomaxillofacial Radiology, Gulhane Training and Research Hospital, Dentistry Center, Turkey \\ ${ }^{2}$ Department of Dentomaxillofacial Radiology, Health Sciences University, Gulhane Dentistry Faculty, Turkey \\ ${ }^{3}$ Department of Dentomaxillofacial Radiology, Ondokuz Mayis University, Turkey \\ ${ }^{4}$ Department of Biostatistics, Yildirim Beyazit University, Turkey \\ ${ }^{5}$ Department of DentoMaxillofacial Radiology, Faculty of Dentistry, Ankara University, Ankara, Turkey \\ ${ }^{6}$ OMFS IMPATH Research Group, Department of Imaging and Pathology, Faculty of Medicine, University of Leuven and Oral and Maxillofacial Surgery, \\ University Hospitals Leuven, Leuven, Belgium
}

\begin{abstract}
INTRODUCTION: Since the first introduced use of cone beam computed tomography (CBCT) in the maxillofacial region it has been increasingly popular. In contrast to 2D imaging modalities such as periapical and panoramic radiographic techniques, $\mathrm{CBCT}$ provides some valuable information from anatomic structures and pathologies. Hence, the anatomical structures can be viewed more accurately than $2 \mathrm{D}$ imaging modalities. In addition, images obtained with $\mathrm{CBCT}$ allow for more appropriate treatment planning. The purpose of this study was to assess the accessory mental foramen (AMF) and retromolar canal which were incidentally found on CBCT images.

ОвјестіVEs: The aim of this study is to reveal the frequency and characteristics of the accessory mental foramen and retromolar canal.

MATERIAL AND METhods: A total of 480 CBCT images obtained from dental implant patients were assessed. Demographic data and accessory mental foramen and mandibular canal variations were noted. All obtained data were analyzed using descriptive statistics.

RESULTS: A total of 480 CBCT images were assessed. 208 (43.33\%) of the patients were female and 272 (56.66\%) were male. A total of $41(8.5 \%)$ accessory mental foramen and $46(9.6 \%)$ mandibular canal variations were discovered on 480 CBCT images. The age range of patients was from 18 to 84 years.

Conclusions: Identification of anatomical structures and their variations can play an important role in implant dentistry. Clinicians commonly prefer conventional radiologic methods to evaluate the dentomaxillofacial region. Although most of the variations are asymptomatic and require no treatment, correct identification of these findings will reduce unnecessary further diagnostic assessments and will provide more appropriate treatment plans.
\end{abstract}

KEY wORDS: CBCT, retromolar canal, accessory mental foramen.

\section{JOURNAL OF STOMATOLOGY CZASOPISMO STOMATOLOGICZNE

AdDress For CORRESPondence: Prof. Kaan Orhan, Department of Dentomaxillofacial Radiology, Ankara University, 06500, Ankara, Turkey, e-mail: call53@yahoo.com 


\section{INTRODUCTION}

The mandibular canal is located within the mandible and contains the inferior alveolar nerve as well as the artery and the vein. It starts at the mandibular foramen which is found on the lingual side of the ramus, continues on the buccal surface of the body of the mandible and ends at the mental foramen. Location, configuration and course of this canal are important in surgical procedures performed on the mandible [1]. Knowledge of the accurate location of the mandibular canal and its anatomical variations such as accessory canals and foramina will allow clinicians to avoid complications [2] Hence, comprehensive and detailed radiographic evaluation should be applied using the appropriate radiologic modality.

Accessory mental foramen is one of the rare anatomical variations of mandible. It is described as the presence of more than one mental foramen in the mental foramen region. According to the literature, the incidence rate varies between $2 \%$ and $10 \%$ depending on ethnicity [3]. Although it is found rarely, the close relationship with the mandibular canal creates a great clinical importance especially in endodontic treatments and surgical procedures such as genioplasty, root resection, and implant placement [4].

The mandibular canal has generally been known to occur as one for each side of the mandible. But since 1973, anatomical variations of the mandibular canal have been reported [5]. The mandibular retromolar canal is an anatomical variation of the mandibular canal and is classically described as a canal that branches off the inferior alveolar canal behind the $3^{\text {rd }}$ molar. It generally follows a postero-superior direction and opens into the retromolar fossa [6].

According to the published studies, the retromolar canal has been generally studied as a subtype of bifid mandibular canal. The other subtypes are described as the dental canal, forward canal and buccolingual canal [5]. The retromolar canal is the most common focused subtype. To the best of our knowledge there are only a few studies mentioning the other types [7]. In addition, the retromolar canal has been classified into type 1, 2 and 3 on the basis of their courses as described by Ossenberg [6]. The incidence of this variation shows differences according to the radiological method used. Incidence rate was reported between less than $1 \%$ to $65.3 \%[8,9]$. The variety of incidence may be due to differences in age groups, target population, sample size or variety of used imaging modalities.

\section{OBJECTIVES}

In clinical dental practice, anatomical variations such as accessory mental foramen or retromolar canal can only be detected radiologically. Although conven- tional two-dimensional modalities are commonly used for radiographic examination in dental practice, due to having some limitations such as magnification, distortion or superimpositions, they provide low detailed, insufficient information of anatomical structures and variations. Therefore, three-dimensional sectional imaging modalities are used to obtain more sufficient and accurate information. Especially CBCT provides detailed multiplanar images of anatomical structures with a lower exposure dose advantage [2, 5]. Other advantages of CBCT are the low cost of the examination compared with CT, fast scanning time, lower number of artefacts and real-time image analysis [10].

This study assessed the accessory mental foramen and retromolar canal which were incidentally found on CBCT images. The aim of this study is to reveal the frequency and characteristics of the accessory mental foramen and retromolar canal.

\section{MATERIAL AND METHODS}

This retrospective study was made using CBCT scans. CBCT images used in the study were acquired on a 3D Accuitomo 170 instrument (3D Accuitomo; J Morita Mfg. Corp., Kyoto, Japan) and were obtained between 2017-2018 from the dental implant patients. The following criteria were used to exclude some images from this study: poor diagnostic quality, small FOV size and presence of a large mandibular pathology. The study sample ( $n=480)$ consisted of CBCT scans of the patients who were referred for dental implant rehabilitation to the Department of Dentomaxillofacial Radiology, Health Sciences University, Gulhane Dentistry Faculty, Ankara, Turkey. All the CBCT images were evaluated by a dentomaxillofacial radiologist who has 12 years of experience on the basis of presence of mandibular canal variations and accessory mental foramen.

All patients were informed about the procedure and gave their informed consent prior to clinical examinations and radiologic evaluation according to the principles of the Helsinki Declaration, including all amendments and revisions. Collected data were noted and only accessible to the researchers.

For CBCT evaluations, proprietary manufacturer software (i-Dixel 2.0/One Data Viewer/One Volume Viewer; J Morita Mfg. Corp.) was used. Images were viewed in a dimly lit room on a 30 inch Dell 3008WFP Flat Panel Monitor (Dell Inc., Round Rock, TX, USA) at a screen resolution of $1920 \times 1200$ pixels and 32-bit color depth. Data were analyzed by descriptive statistics. The occurrence frequency of incidentally found accessory mental foramen or retromolar canal was noted. Range was used to describe the age of the patients. Statistical analyses were performed using the SPSS software (version 15.0; SPSS Inc., Chicago, IL, USA) and MS Excel 2003. 


\section{RESULTS}

A total of 480 CBCT images were assessed. Among the patients $208(43.33 \%)$ were female and 272 (56.66\%) were male. A total of 41 (8.5\%) accessory mental foramen and 46 (9.6\%) mandibular canal variations were discovered on 480 CBCT images. The age range of patients was from 18 to 84 years. Bilateral mandibular canal variations were detected in 11 patients (Figure 1).
Thirty-five of 46 patients had unilateral mandibular canal variations. One of them was found as trifid mandibular canal (Figure 2). There were also detected 42 accessory mental foramina in 41 patients. A total of 41 patients had a unilateral accessory mental foramen (Figure 3) and only one had two accessory mental foramina unilaterally (Figure 4). The distribution of mandibular canal variations and accessory mental foramen in the study group according to gender is presented in Table 1.

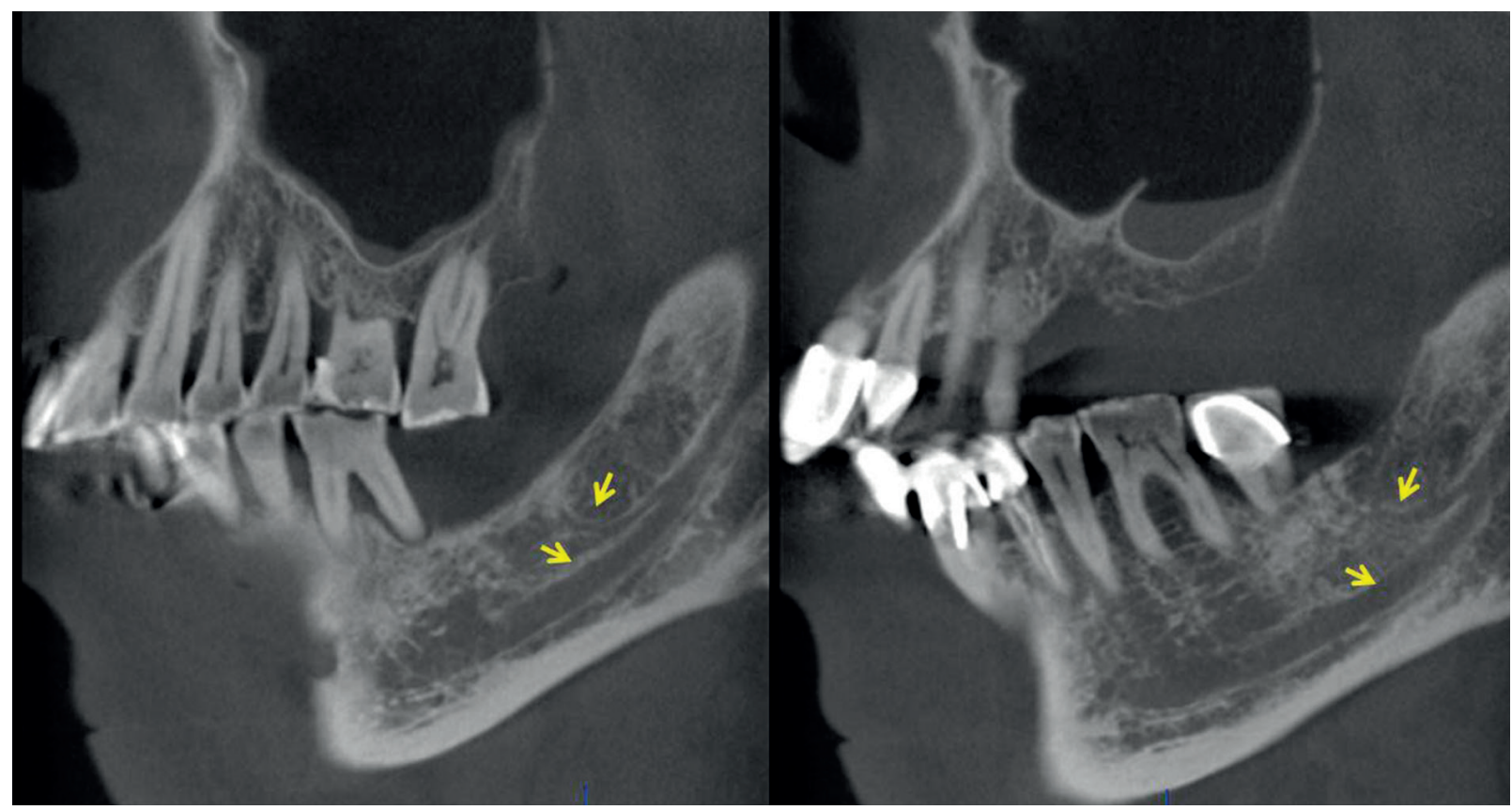

FIGURE 1. Sagittal and coronal view of a cone beam computed tomography image of 72-year-old man. Arrows show bilateral mandibular canal variations

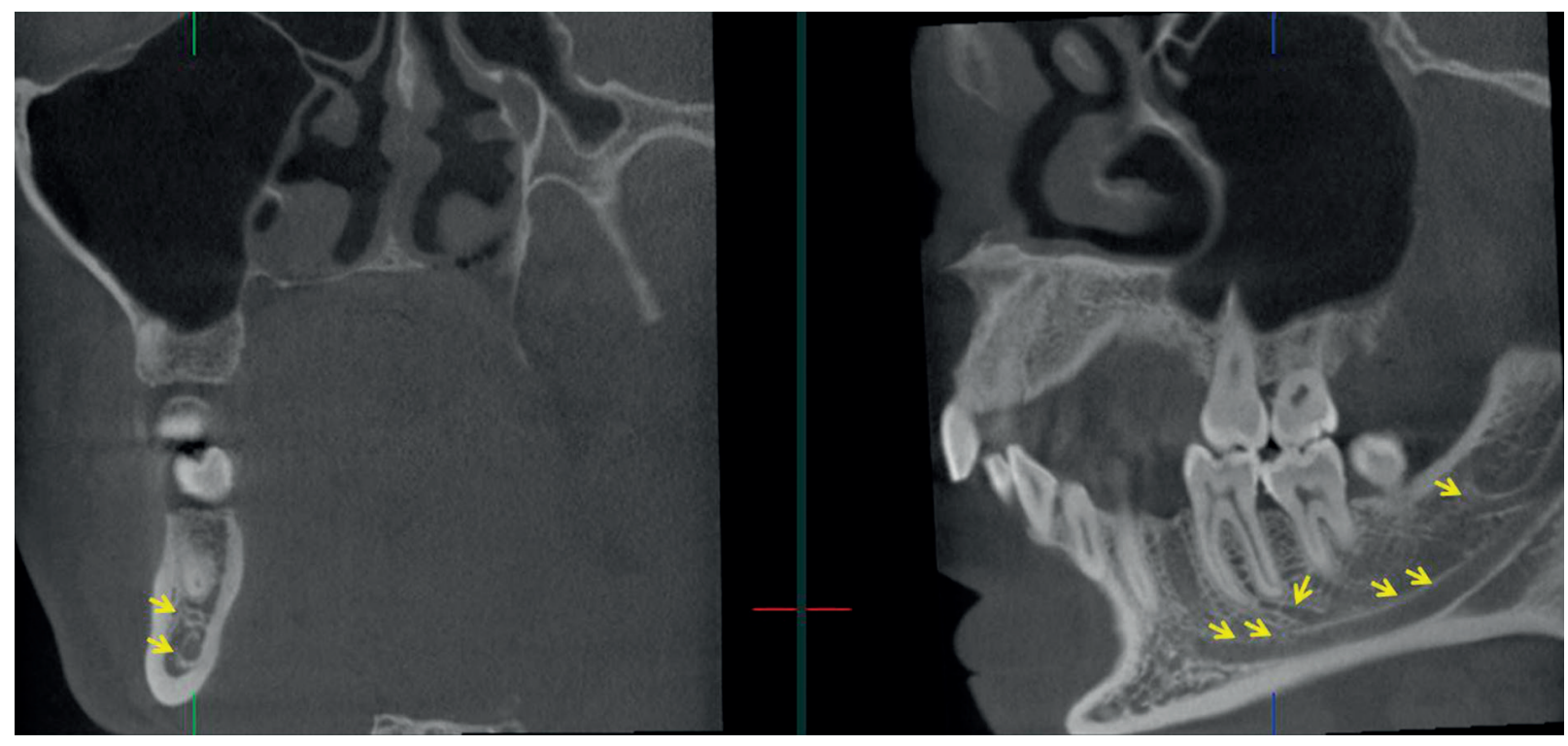

FIGURE 2. Sagittal and coronal view of a cone beam computed tomography image of 30-year-old man. Arrows show unilateral mandibular canal variation described as trifid mandibular canal 


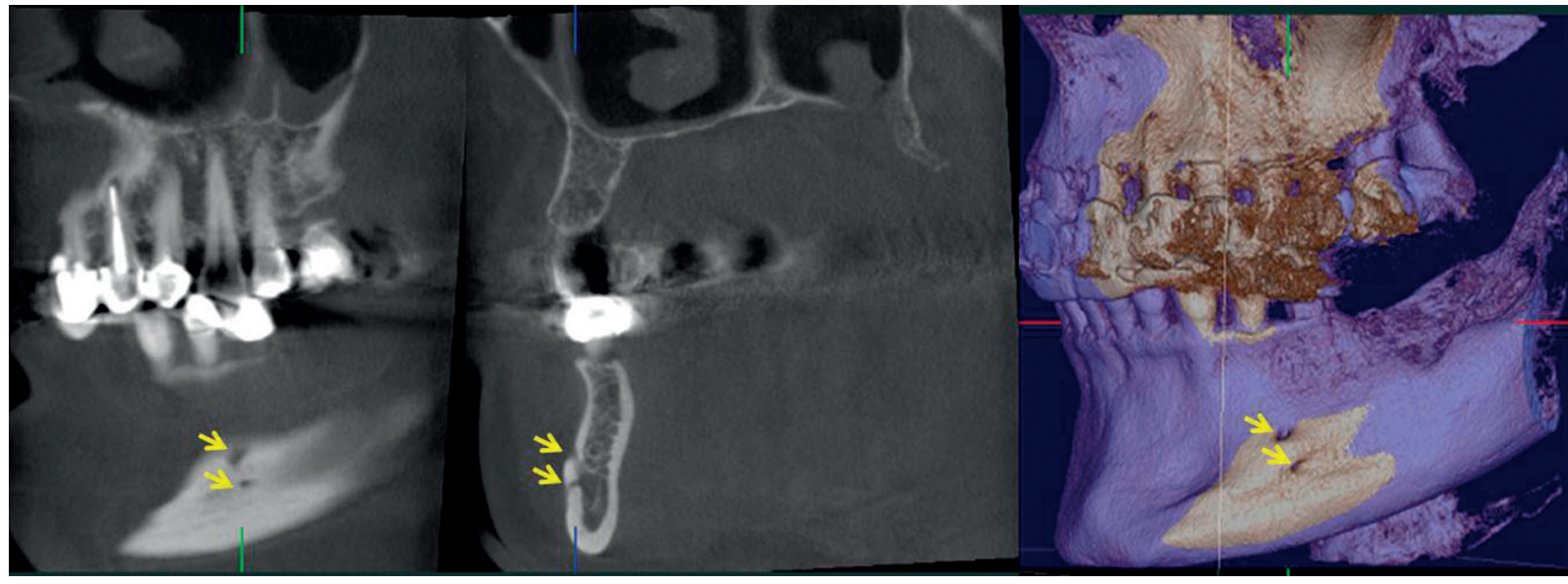

FIGURE 3. Sagittal, coronal and 3D reconstruction a cone beam computed tomography image of a 58-year-old woman. Arrows show an accessory mental foramen on the left side of the mandible

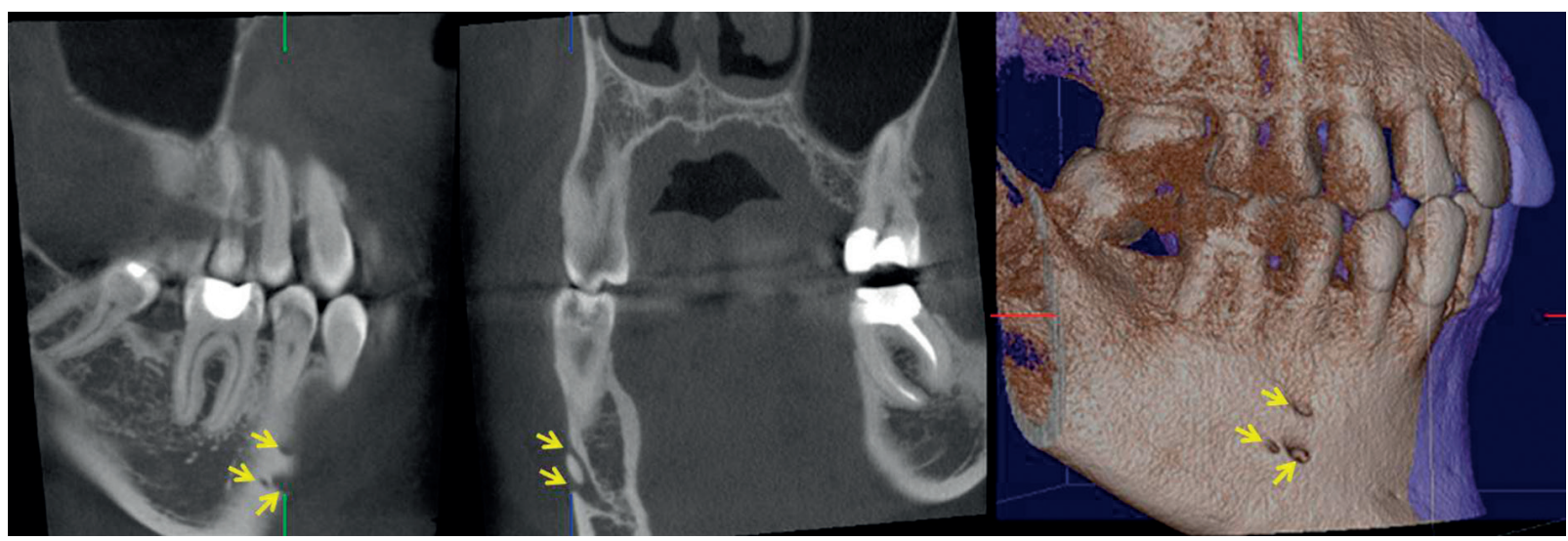

FIGURE 4. Sagittal, coronal and 3D reconstruction a cone beam computed tomography image of a 45-year-old man. Arrows show double accessory mental foramens on the right

TABLE 1. Distribution of mandibular canal variations and accessory mental foramen in the study group according to gender

\begin{tabular}{|c|c|c|c|c|c|}
\hline \multirow[b]{2}{*}{ Gender } & \multicolumn{2}{|c|}{ Variation of mandibular canal } & \multicolumn{2}{|c|}{ Variation of mental foramen } & \multirow{2}{*}{ Total (\%) } \\
\hline & NA (\%) & Available (\%) & NA (\%) & Available (\%) & \\
\hline Female & 195 (93.8) & $13(6.2)$ & 195 (93.8) & $13(6.2)$ & $208(100)$ \\
\hline Male & 239 (87.9) & $33(12.1)$ & 244 (89.7) & $28(10.3)$ & $272(100)$ \\
\hline Total & $434(90.4)$ & $46(9.6)$ & 439 (91.5) & $41(8.5)$ & $480(100)$ \\
\hline
\end{tabular}

\section{DISCUSSION}

The presence of the supplementary mental foramen on the mandible is considered to be a rare anatomical formation. It has been suggested to result from the branching of the mental nerve before it exits the mental foramen [11]. Neglecting the AMF can cause damage of the neurovascular bundle. This variation has been noted more with the emergence of cone-beam computed tomography scan [12]. It can be said that the orthopantomogram is inadequate to detect the accessory foramen [4].
Studies about AMF revealed that the accessory mental foramen is variable in different ethnic groups [13]. In research the prevalence of AMF ranges from 1.4 to more than $20 \%[13,14]$. This wide range may be related to ethnic group variabilities; also it can be based on the differences of the methodology and definition of AMF [15].

A study done by Balcioglu and Kocaelli detected a prevalence of AMF ranging from 1.4 to $10 \%$. Also it was found that non-Caucasians have a higher prevalence of AMF than Caucasians [16]. On the other hand, according to Polguj and colleagues' study AMF is con- 
sidered a much more common anatomic variation than double suprascapular foramen, which is a rare skeletal variation [17].

It was reported that the highest prevalence of AMF was in black and Maori males [18]. Another study performed in Turkey showed that $6.5 \%$ of the Turkish population had AMF [19]. If we look at the other performed studies, AMFs were identified in Greeks in 6.68\% [20], in Japanese in 7\% [1], in Sri Lankans in 3.92\% [21], and in Indians in $8.9 \%$ [22] of the population. In our study, 41 of the 480 CBCT images showed AMF and a prevalence of $8.5 \%$ occurred. Kalender et al. found a lower prevalence of $6.5 \%$ in the Turkish population [19]. We cannot say that these percentages are similar. The study of Kalender et al. was performed in a group that is about one third smaller than this study. So this ratio among the groups may have affected the results.

In the Chinese population the prevalence of AMF was 7.3\% [15] and another study which was performed in Korean people showed a prevalence of $8.1 \%$ [23]. These results are similar, so they confirm Hanihara and Ishida, who stated that population and geographic variations have a significant role in the frequency of AMF [14].

Embryologically with the development of the mandibular bone AMF came into view. After the maturation of the mandible the frequency of AMF does not change [24]. So further studies of AMF should be performed on younger subjects. After our study another study was conducted in Turkey in the 13-14 age group; they obtained a result of AMF prevalence as $11.6 \%$, a rather high result compared to ours [25].

Ramification of the mandibular canal is an anatomic variation having a fine neurovascular bundle containing veins, arteries and nerve fibers [8]. So not being aware of this variation can cause some complications such as hemorrhage and paresthesia during some operations of that region such as implant treatment, tooth extractions, etc. [26].

On the other hand, ramification of the mandibular canal may make alveolar nerve block anesthesia difficult to provide [8].

The study performed by Leite et al. found the second most common anatomic variation, ramification of the mandibular canal, at a percentage of $12 \%$ [26]. When CBCT images were evaluated for this variation, some researchers found a rate of $19 \%$ [27], while others found $65 \%$ [1]. In our work in which we evaluated the CBCT images, we found the ramification of the mandibular canal in 46 of the 480 images, so a percentage of $9.6 \%$ was detected.

In a study in which the literature was reviewed in 2007 it was detected that in panoramic radiography evaluations the prevalence of AMF decreases. This decrease in frequency can range from $0.08 \%$ to $8.3 \%$ [28]. A case which supports this result was written by Tolentino. In this case while no variation was observed in the panoramic radiography, variations appeared in CBCT imag- es [29]. Therefore researchers argue that panoramic radiography is not reliable in detecting the variations [27].

In conclusion, accurate diagnosis and correct identification of this anatomical variation will allow the practitioners to avoid nerve damage, bleeding and complications [30]. Hence comprehensive and detailed preoperative radiologic assessment should be performed by using the appropriate imaging modality.

\section{CONFLICT OF INTEREST}

The authors declare no potential conflicts of interest with respect to the research, authorship, and/or publication of this article.

\section{References}

1. Naitoh M, Hiraiwa Y, Aimiya H, Ariji E. Observation of bifid mandibular canal using cone-beam computerized tomography. Int J Oral Maxillofac Implants 2009; 24: 155-159.

2. Lizio G, Pelliccioni GA, Ghigi G, et al. Radiographic assessment of the mandibular retromolar canal using cone-beam computed tomography. Acta Odontol Scand 2013; 71: 650-655.

3. Igarashi C, Kobayashi K, Yamamoto A, et al. Double mental foramina of the mandible on computed tomography images: a case report. Oral Radiol 2004; 20: 68-71.

4. Imada TS, Fernandes LM, Centurion BS, et al. Accessory mental foramina: prevalence, position and diameter assessed by conebeam computed tomography and digital panoramic radiographs. Clin Oral Implants Res 2014; 25: e94-99.

5. Orhan K, Aksoy S, Bilecenoglu B, et al. Evaluation of bifid mandibular canals wit cone-beam computed tomography in a Turkish adult population: a retrospective study. Surg Radiol Anat 2011; 33: 501-507.

6. Ossenberg NS. Retromolar foramen of the human mandible. Am J Phys Anthropol 1987; 72: 119-128.

7. Pyle MA, Jasinevicius TR, Lalumandier JA, et al. Prevalence and implications of accessory retromolar foramina in clinical dentistry. General Dent 1999; 47: 500-503.

8. Bilecenoglu B, Tuncer N. Clinical and anatomical study of retromolar foramen and canal. J Oral Maxillofac Surg 2006; 64: 1493-1497.

9. Suazo GI, Zavando MD, Cantin LM. Retromolar canal and foramen prevalence in dried mandibles and clinical implications. Int J Odontostomat 2008; 2: 183-187.

10. Miracle AC, Mukherji SK. Cone beam CT of the head and neck, part 1: physical principles. AJNR Am J Neuroradiol 2009; 30: 1088-1095.

11. Zmysłowska-Polakowska EZ, Radwański M, Łęski M, et al. The assessment of accessory mental foramen in a selected Polish population: a CBCT study. BMC Med Imaging 2017; 17 : 17.

12. Katakami K, Mishima A, Shiozaki K, et al. Characteristics of accessory mental foramina observed on limited cone-beam computed tomography images. J Endod 2008; 34: 1441-1445.

13. Sawyer DR, Kiely ML, Pyle MA. The frequency of accessory mental foramina in four ethnic groups. Arch Oral Biol 1998; 43: 417-420.

14. Hanihara T, Ishida H. Frequency variations of discrete cranial traits in major human populations IV. Vessel and nerve related variations. J Anat 2001; 199: 273-287.

15. Li Y, Yang X, Zhang B, et al. Detection and characterization of the accessory mental foramen using cone-beam computed tomography. Acta Odontol Scand 2018; 76: 77-85.

16. Balcioglu HA, Kocaelli H. Accessory mental foramen. North Am J Med Sci 2009; 1: 314-315. 
17. Polguj M, Podgórski M, Jędrzejewski K, Topol M. The double suprascapular foramen: unique anatomical variation and the new hypothesis of its formation. Skeletal Radiol 2012; 41: 1631-1636.

18. Kieser J, Kuzmanovic D, Payne A, et al. Patterns of emergence of the human mental nerve. Arch Oral Biol 2002; 47: 743-747.

19. Kalender A, Orhan K, Aksoy U. Evaluation of the mental foramen and accessory mental foramen in Turkish patients using conebeam computed tomography images reconstructed from a volumetric rendering program. Clin Anat 2012; 25: 584-592.

20. Zografos J, Mutzuri A. Incidence of double mental foramen in a sample of Greek population. Odontostomatol Proodos 1989; 43: 521-523.

21. Ilayperuma I, Nanayakkara G, Palahepitiya N. Morphometric analysis of the infraorbital foramen in adult Sri Lankan skulls. Int J Morphol 2010; 28: 777-782.

22. Sankar DK, Bhanu SP, Susan PJ. Morphometrical and morphological study of mental foramen in dry dentulous mandibles of South Andhra population of India. Indian J Dent Res 2011; 22: 542-546,

23. Han SS, Hwang JJ, Jeong HG. Accessory mental foramina associated with neurovascular bundle in Korean population. Surg Radiol Anat 2016; 38: 1169-1174.

24. Iwanaga J, Saga T, Tabira Y, et al. The clinical anatomy of accessory mental nerves and foramina. Clin Anat 2015; 28: 848-856.

25. Gümüşok M, Akarslan ZZ, Bașman A, Üçok Ö. Evaluation of accessory mental foramina morphology with cone-beam computed tomography. Niger J Clin Pract 2017; 20: 1550-1554.

26. Leite GM, Lana JP, Machado VC, et al. Anatomic variations and lesions of the mandibular canal detected by cone beam computed tomography. Surg Radiol Anat 2014; 36: 795-804.

27. Oliveira-Santos C, Souza PH, Azambuja Berti-Couto S, et al Assessment of variations of the mandibular canal through cone beam computed tomography. Clin Oral Investig 2012; 16: 387-393.

28. Rouas P, Nancy J, Bar D. Identification of double mandibular canals: literature review and three case reports with CT scans and cone beam CT. Dentomaxillofac Radiol 2007; 36: 34-38.

29. de Souza Tolentino E, Silva PA, Pagin O, et al. Uncommon trajectory variations of the mandibular canal and of the mandibular incisive canal: case report. Surg Radiol Anat 2013; 35: 857-861.

30. Avsever H, Gündüz K, Özgedik S, et al. Multiple accessory mental foramen: a rare anatomical finding. Dentistry Advanced Research 2017; DTAR-135. 